\title{
Optimal Design of a MW Class SCSG for a Tidal Current Power Generation System
}

\author{
Byeong-Soo Go*, Hae-Jin Sung*, Minwon Park* and In-Keun Yu ${ }^{\dagger}$
}

\begin{abstract}
A superconducting synchronous generator (SCSG) can be expected to decrease the size and weight compared to conventional tidal current generators. This paper proposes an optimal design of a $2 \mathrm{MW}$ class SCSG for a tidal current power generation system. The proposed optimal design of the SCSG will reduce the length of the high-temperature superconducting wire as well as the weight and volume of the SCSG. The 3D finite element method is used to analyze the magnetic field distribution. The optimized $2 \mathrm{MW}$ SCSG is compared with a $2 \mathrm{MW}$ conventional generator. As the optimized SCSG is more compact and lighter than a conventional generator, it will be efficiently applied to practical tidal power systems.
\end{abstract}

Keywords: High-temperature superconductor, Superconducting generator, Tidal current power generation system

\section{Introduction}

Tidal currents are attractive sources of renewable energy due to their predictability and high energy density, in general. The density of water is 840 times higher than the density of air and hence, a greater amount of power can be harvested from a smaller domain than wind turbines $[1,2]$.

Tidal current turbines can be classified into geared and gearless types. A gearless turbine has a higher efficiency, as well as lower maintenance costs than the geared type. However, due to it's lager size and rotating speed, it becomes less efficient at generating power [3]. A gearless type superconducting synchronous generator (SCSG) is proposed as a tidal current power generation system because the SCSG has a high torque and a simplified mechanical structure $[4,5]$.

This paper presents an optimal design of a $2 \mathrm{MW}$ class SCSG for a tidal current power generation system by optimizing the method using a 3D Finite Element Method (FEM) program. The 3D FEM program is used to analyze the magnetic field distribution, and the 3D CAD program shows the detailed structure and calculates the weight of the SCSG. This optimal method offers a simple and systematic approach to optimizing the design for performance, quality, and cost. The design's purpose is to reduce the length of the High-Temperature Superconducting (HTS) wire, as well as the weight and volume of the SCSG to ensure a low-cost tidal current power generation system. The optimized 2 MW SCSG is compared with a $2 \mathrm{MW}$ conventional generator from the perspective of the weight and volume of the generator in order to demonstrate the

$\dagger \quad$ Corresponding Author: Dept. of Electrical Engineering, Changwon National University, Korea. (yuik@cwnu.co.kr)

* Dept. of Electrical Engineering, Changwon National University, Korea. (iopewq1@gmail.com)

Received: February 11, 2014; Accepted: June 23, 2015 most efficient design for the MW class tidal current turbine.

As a result, the optimized design of the gearless SCSG turbine is more efficient, lighter, and more compact than the conventional generator. Therefore, the mechanical stress and construction costs associated with the tidal current power generation system can be reduced. The optimized design of the SCSG can be effectively utilized to develop MW class tidal current power generation systems.

\section{Overview of a Tidal Current Turbine}

Tidal current resources can be analogized to energy extraction from wind. The kinetic energy in a water channel is proportional to the cube of the velocity of the water passing through the cross section of that channel. The energy is calculated by Eq. (1).

$$
E=\frac{1}{2} \rho A V^{3}
$$

where, $\rho$ is the density of sea-water $\left(\mathrm{kg} / \mathrm{m}^{3}\right), A$ is the cross sectional area of the channel $\left(\mathrm{m}^{2}\right)$, and $V$ is the flow velocity perpendicular to the cross section of the channel $(\mathrm{m} / \mathrm{s})$. However, a tidal current turbine can only harness a fraction of this power due to losses, so Eq. (1) is modified to Eq. (2).

$$
E=\frac{1}{2} \rho C_{p} A V^{3}
$$

where, $C_{p}$ is known as the power coefficient and is essentially the percentage of power that can be extracted from the fluid current and takes into account losses due to Betz's law $[5,6]$. 


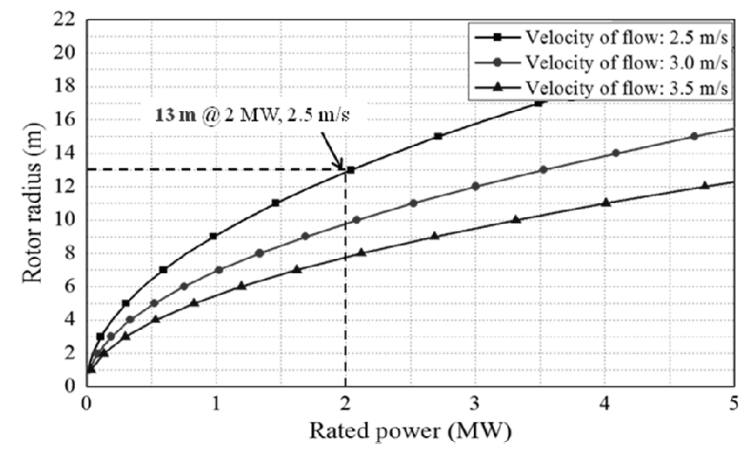

(a) Rotor radius depending on the rated power

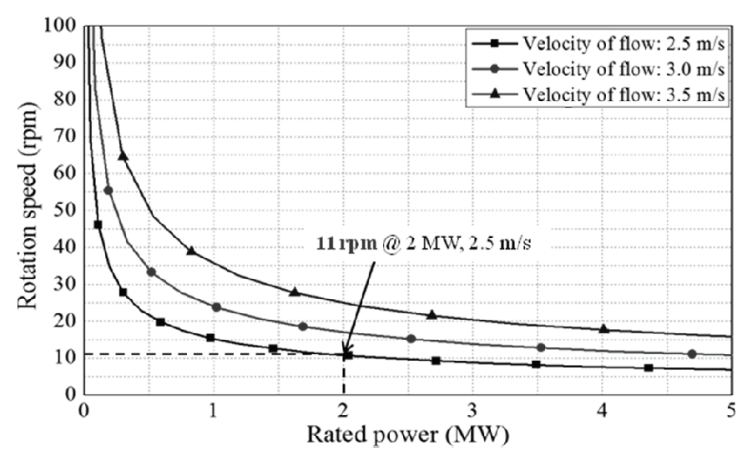

(b) Rotating speed depending on the rated power

Fig. 1. The rotor radius and rated rotating speed of the SCSG

For the conceptual design of a $2 \mathrm{MW}$ class gearlesstype SCSG, the design specifications of $2 \mathrm{MW}$ class conventional tidal current turbines should be defined. The rotor radius $(\mathrm{R})$ and rated rotating speed (RPM) of a tidal current turbine are calculated by Eqs. (3) and (4).

$$
\begin{gathered}
R=\sqrt{\frac{2 \times P}{\pi \times C_{p} \times \rho \times V_{\text {tide }}^{3}}} \\
R P M=\frac{30 \times \omega_{\text {blade }}}{\pi}=\frac{60 \times \lambda \times V_{\text {tide }}}{2 \times \pi \times R}
\end{gathered}
$$

where, the $C_{p}$ and $\rho$ are 0.48 and $1,025 \mathrm{~kg} / \mathrm{m}^{3}$, respectively [3]. Fig. 1 shows the rotor radius and rated rotating speed of a tidal current turbine depending on the rated power.

When the rated power of a tidal current turbine increases, the rotor radius grows to get more power from tidal energy. The rotor radius of the $2 \mathrm{MW}$ class tidal current turbines is $13 \mathrm{~m}$, and the rated rotating speed is $11 \mathrm{rpm}$ at flow velocity of $2.5 \mathrm{~m} / \mathrm{s}$.

Compared to the wind turbine at the same capacity, the rotor radius is significantly decreased by the high density of water. Conversely, the generator radius is increased to generate the same torque when the rotating speed is slower than the wind turbine.

Fig. 2 shows the layout of a conventional tidal current turbine.

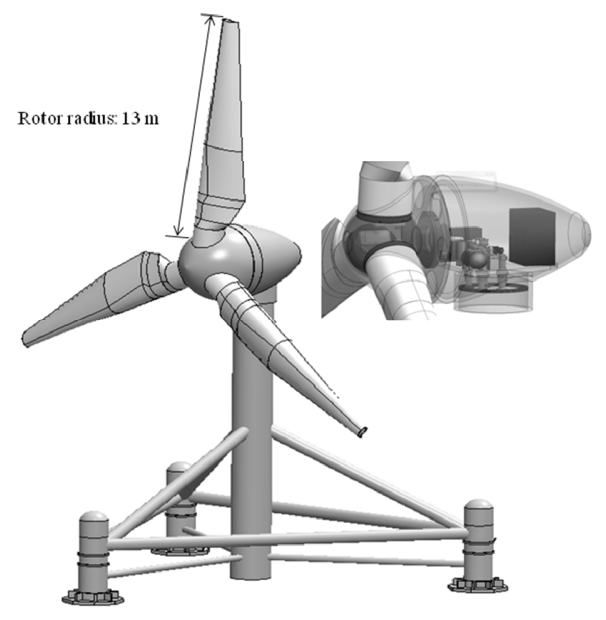

Fig. 2. Layout of a $2 \mathrm{MW}$ class tidal current turbine

\section{Optimal Design of a SCSG for Tidal Current Turbines}

\subsection{Fundamental structure of the SCSG}

In order to operate the SCSG with full variable speed, the generator is connected to the power grid through a full scale frequency converter. The frequency converter is composed of a generator side rectifier, a DC link, and a grid side inverter. Fig. 3 shows the schematic diagram of the SCSG.

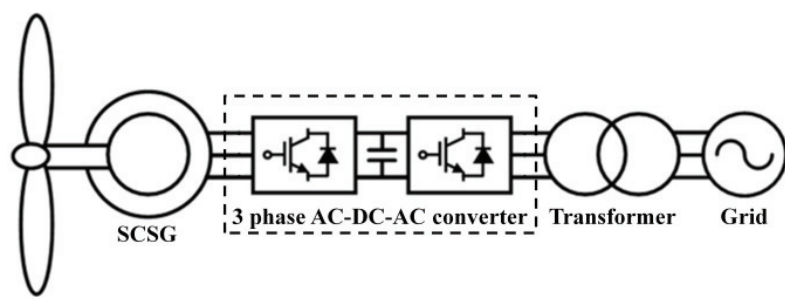

Fig. 3. Schematic diagram of the gearless type SCSG

The SCSG is composed of the HTS rotor coil, rotor body, vacuum vessel, stator coil, stator teeth, and magnetic shield. Fig. 4 illustrates the configuration of the SCSG. The rotor poles consist of a racetrack-type double pancake coil (DPC) using an HTS wire. The HTS wire of the rotor coil is coated with long, flat conductor tape with a thickness of $0.1 \mathrm{~mm}$ and width of $4 \mathrm{~mm}$. The rotor body, vacuum shield, and stator teeth consist of nonmagnetic material to prevent iron loss. Laminated silicon steel is used at the magnetic shield. The SCSG is not equipped with a damper winding. In the case of the SCSG being connected to a frequency converter, which provides a variable stator frequency according to the actual rotor speed, no relative movement between the stator and rotor field exists. The copper stator winding has double-layered and distributed three-phase winding [7-10]. 


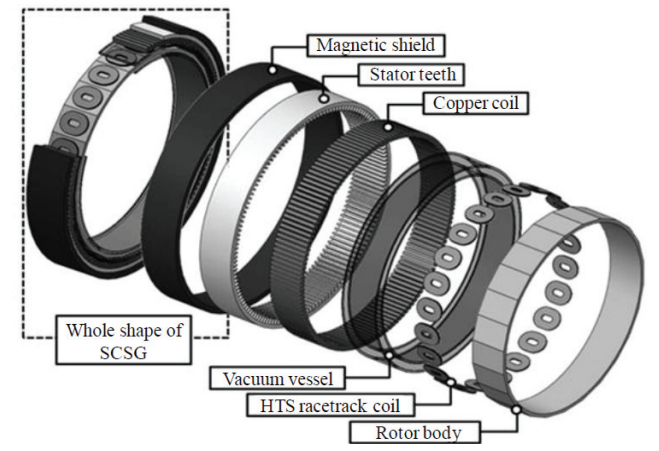

(a) Whole shape of the SCSG

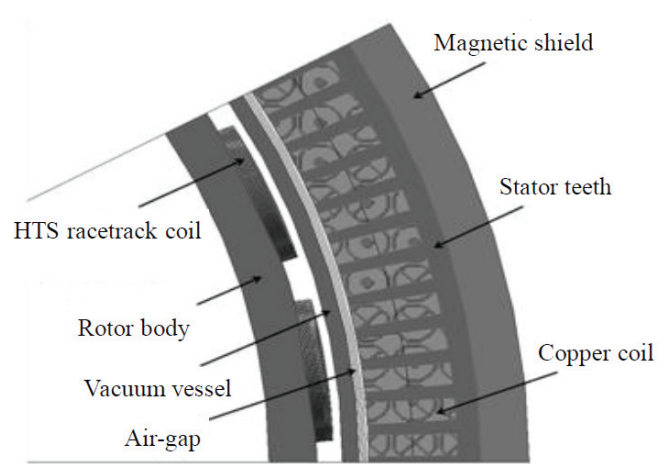

(b) $1 / 28$ model of the SCSG

Fig. 4. Configuration of the SCSG

\subsection{Design procedure of the optimization method}

Here, the 2 MW class SCSG is designed based on the optimization procedure, suggested in Fig. 5. Three major factors of the SCSG are investigated in this paper: the length of the HTS wire, the weight, and the volume. The four control parameters are selected, including the number of poles, the number of DPC layers, and the turns of the HTS field coil and the stator coil.

Initially, the number of rotor poles of the generator is adjusted to reduce its diameter to less than $6.0 \mathrm{~m}$. The next step is to change the number of DPC layers, and HTS field coil and stator coil turns to generate $2 \mathrm{MW}$ output power. The HTS field current of the generator is gauged by a perpendicular magnetic field - the critical current curve of HTS wire. Finally, the generator can be specifically designed by changing the axial length of the HTS coil to achieve a minimum volume and weight. The HTS field coil turns are controlled to generate rated power because the electromotive force is transformed by changing the axial length.

\subsection{Optimal design of the 2 MW SCSSG for tidal current turbines}

In the $2 \mathrm{MW}$ class tidal current turbines, the rotor radius and rated rotating speed are $13 \mathrm{~m}$ and $11 \mathrm{rpm}$, respectively, at a flow velocity of $2.5 \mathrm{~m} / \mathrm{s}$. The density of water is 1,025 $\mathrm{kg} / \mathrm{m}^{3}$. The water density is 840 times higher than the

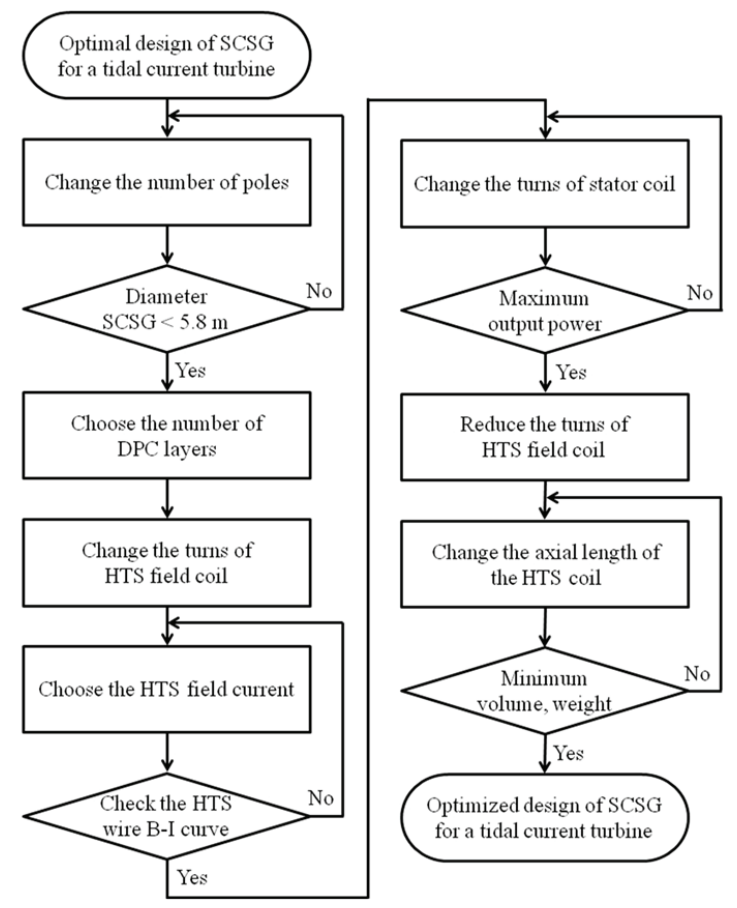

Fig. 5. Optimal design procedure for the tidal current SCSG

Table 1. Basic specifications of the designed 2 MW SCSG

\begin{tabular}{c|c}
\hline Items & Value \\
\hline Rated power & $2 \mathrm{MW}$ \\
\hline Rated line to line voltage & $690 \mathrm{~V}$ \\
\hline Rated armature current & $1,673 \mathrm{~A}$ \\
\hline Rated rotation speed & $11 \mathrm{rpm}$ \\
\hline Rated torque & $1.74 \mathrm{MNm}$ \\
\hline Number of poles & 28 \\
\hline Number of stator coils/phases/poles & 2 \\
\hline Rated frequency & $2.56 \mathrm{~Hz}$ \\
\hline
\end{tabular}

Table 2. Detail specifications of the designed 2 MW SCSG

\begin{tabular}{c|c}
\hline Items & Value \\
\hline Operating temperature & $20 \mathrm{~K}$ \\
\hline DPC turns & 840 \\
\hline Stator coil turns & 6 \\
\hline Number of DPC layers & 5 \\
\hline Operating current of DPC & $135 \mathrm{~A}$ \\
\hline Outer radius of generator & $4,631 \mathrm{~m}$ \\
\hline Optimized axial length & $400 \mathrm{~m}$ \\
\hline
\end{tabular}

density of air. The line-to-line voltage of the generator is $690 \mathrm{~V}$. Table 1 represents the specifications of the $2 \mathrm{MW}$ SCSG for tidal current turbines. Table 2 indicates the detail specifications of the optimized $2 \mathrm{MW} \mathrm{SCSG}$ for tidal current turbine.

Fig. 6 shows the comparative analysis results of the designed $2 \mathrm{MW}$ class SCSG according to the optimal design procedure in terms of the weight and volume of the generator and total length of HTS wires. In the case of 400 $\mathrm{mm}$ axial length, the weight and volume of the generator, as well as the total length of the HTS wire are the smallest SCSG. 

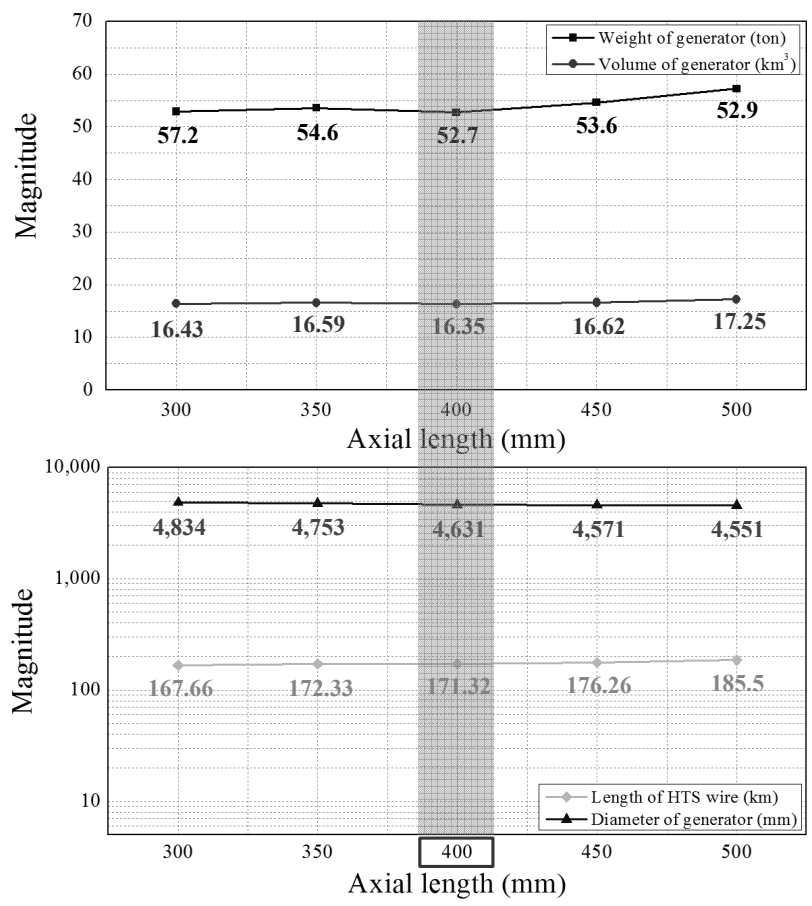

Fig. 6. Comparative analysis results of the designed $2 \mathrm{MW}$ SCSG according to the axial length

\section{Analysis Results and Discussion}

\subsection{D FEM analysis results of the optimized $2 \mathrm{MW}$ SCSG}

Fig. 7 shows the magnetic field distribution for the $1 / 28$ model of the optimized SCSG. The maximum magnetic field is $5.82 \mathrm{~T}$. The HTS wire is influenced by the perpendicular magnetic field because the HTS wire has a tape-like shape. Therefore, the operating current is selected according to the value of the perpendicular magnetic field.

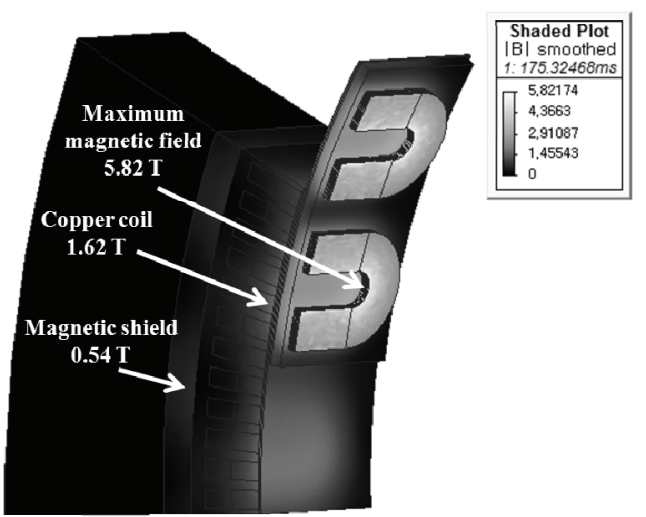

Fig. 7. Magnetic field distribution of the $2 \mathrm{MW} \mathrm{SCSG}$

Fig. 8 shows the perpendicular magnetic field of the optimized $2 \mathrm{MW} \mathrm{SCSG}$. The perpendicular magnetic field is $4.6 \mathrm{~T}$. The measurement position of the perpendicular

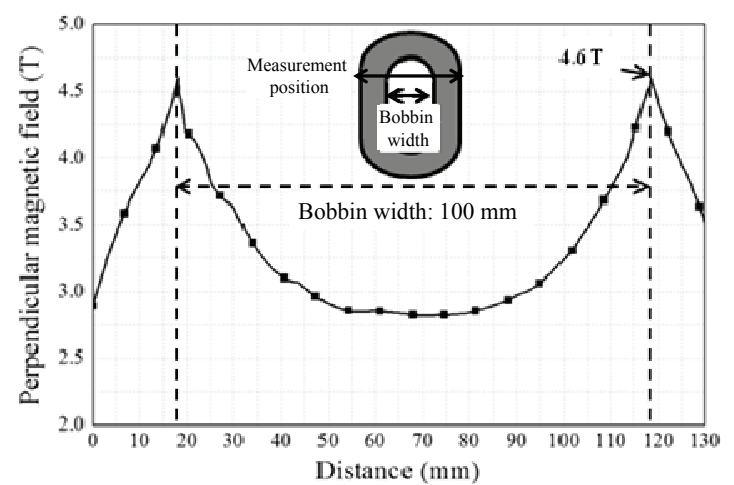

Fig. 8. Perpendicular magnetic field of the $2 \mathrm{MW} \mathrm{SCSG}$

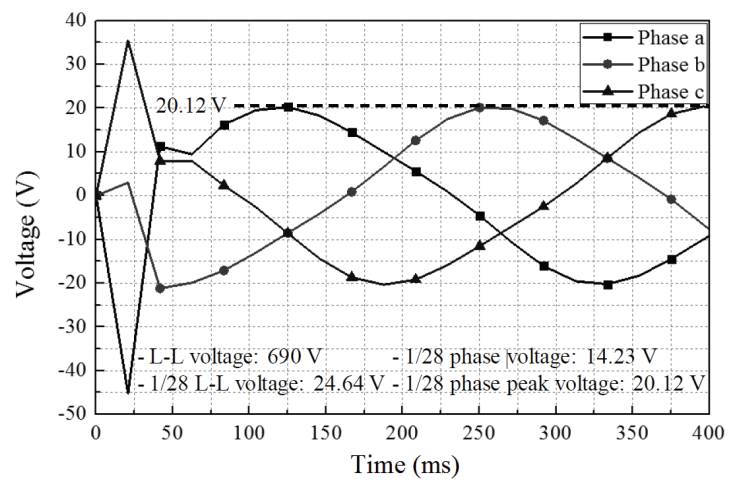

(a) Output voltage of the optimal designed SCSG

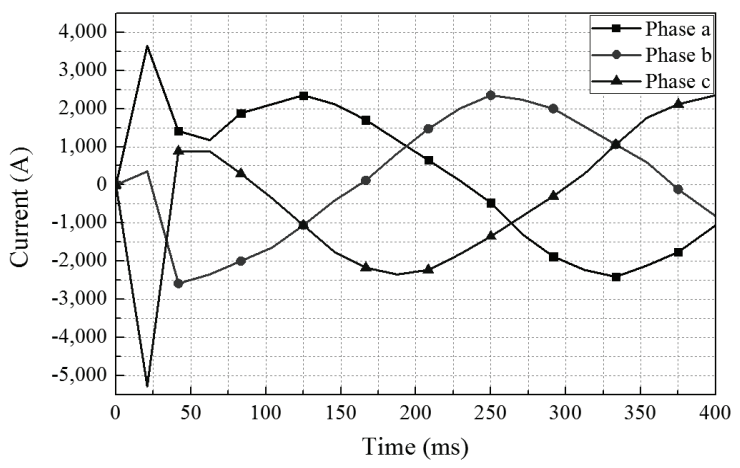

(b) Output current of the optimal designed SCSG

Fig. 9. Output voltage and current of the designed 1/28 model

magnetic field is also given in Fig. 8. The operating current of the HTS wire, applying $80 \%$ of the rated current for safety margin, is $135 \mathrm{~A}$.

The generated output voltage and current of the $1 / 28$ model of the $2 \mathrm{MW} \mathrm{SCSG}$ is illustrated in Fig. 9. The voltage and current are $14.23 \mathrm{~V}$ and 1,673 A, respectively.

\subsection{Comparative analysis with a conventional generator}

The optimized SCSG has a total diameter of $4,631 \mathrm{~mm}$, and the axial length of the DPC is $400 \mathrm{~mm}$. The volume 
and weight of the generator are $16.35 \mathrm{~m}^{3}$ and 52.7 tons, respectively. The total length of the HTS wire is shortest at $171.32 \mathrm{~km}$. The active weights of the SCSG and the PMSG are similar. However, inactive weight of the SCSG including the torque disk and generator frame is much lighter than the PMSG because the volume of the SCSG is smaller than that of the PMSG. As a result, the total weight of the optimized $2 \mathrm{MW} \mathrm{SCSG}$ is less than the $2 \mathrm{MW}$ PMSG.

\section{Conclusion}

This paper presented an optimal design of a $2 \mathrm{MW}$ class SCSG for a tidal current power generation system. An optimizing procedure was used to reduce the length of the HTS wire as well as the weight and volume of the $2 \mathrm{MW}$ SCSG. Then the SCSG was redesigned considering the axial length of the DPC. The magnetic field distribution was analyzed by the 3D FEM. As a result, the volume and weight of the $2 \mathrm{MW} \mathrm{SCSG}$ for tidal current turbines were $16.35 \mathrm{~m}^{3}$ and 52.7 tons, respectively.

The results showed that the optimized 2 MW SCSG could be about two to three times smaller than a $2 \mathrm{MW}$ PMSG. The mechanical stress and the construction costs were reduced because the weight of the support structure was decreased. The optimized design of the SCSG can be effectively utilized to develop MW class tidal current power generation systems.

\section{Acknowledgements}

This research was financially supported by Ministry of Education and National Research Foundation of Korea (NRF) through the Human Resource Training Project Regional Innovation.

\section{References}

[1] Gunjin S. Bir, Michael J. Lawson and Ye Li, "Structual Design of a Horizontal-Axis Tidal Current Turbine Composite Blade," ASME Trans. Offshore and Arctic Engineering, Jun. 2011.

[2] Fraenkel, "Power from Marine Currents," Proceedings of the Institution of Mechanical Engineers, Part A: Journal of Power and Energy, pp. 1-14, 2000.

[3] H. Polinder, F. F. A. van der Pijl, G. -J. De Vilder, and P. J. Tavner, "Comparison of direct-drive and geared generator concepts for wind turbines," IEEE Trans. Energy Convers., vol.21, no.3, pp.725-733, Sep. 2006.

[4] A. McDonald, "Structural analysis of low speed, high torque electrical generators for direct drive renewable energy converters," Ph.D. dissertation, School of
Engineering \& Electronics, University of Edinburgh, 2008.

[5] Hochang Jung, Cheol-Gyun Lee, Sung-Chin Hahn and Sang-Yong Jung, "Optimal Design of a DirectDriven PM Wind Generator Aimed at Maximum AEP using Coupled FEA and Parallel Computing GA," Journal of Electrical Engineering \& Technology, vol. 3, no. 4, pp.552-558, 2008.

[6] Yong-Min You, Hai Lin, and Byung-Il Kwon, "Optimal Design of a Distributed Winding Type Axial Flux Permanent Magnet Synchronous Generator," Journal of Electrical Engineering \& Technology, vol.7, no.1, pp.69-74, 2012.

[7] Naoki Maki, Tomoaki Takao, Shuichiro Fuchino, Hiromichi Hiwasa, Masazumi Hirakawa, Kagao Okumura, Minoru Asada, and Ryuukichi Takahashi, "Study of practical applications of HTS synchronous machines," IEEE Trans. Appl. Supercond., vol.15, no. 2, pp. 2166-2169, Jun. 2005.

[8] Hiroyuki Ohsaki, Yutaka Terao, Rashidul M. Quddes and Masaki Sekino, "Electromagnetic Characteristics of 10 MW Class Superconducting Wind Turbine Generators," IEEE Electrical Machine and system (ICEMS), pp. 1303-1306, 2010.

[9] A.B. Abrahamsen, N. Mijatovic, E. Seiler, T. Zirngibl, C. Traeholt, P. B. Norgard, N. F. Pedersen, N. H. Andersen, and J. Ostergard, "Superconducting wind turbine generators," Superconductor Science and Technology, vol.23, pp.1-8, Feb. 2010.

[10] C. Lewis, J. Muller, "A Direct Drive Wind Turbine HTS Generator", IEEE Power Engineering Society General Meeting 2007, pp.1-8, 2007.

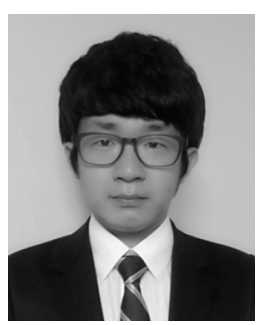

Byeong-Soo Go He received B.S. and M.S. degrees in Electrical Engineering from Changwon National University in 2013 and 2015, respectively. His research interests are wind turbine, tidal current turbine and superconducting generators.

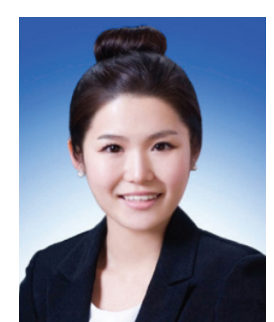

Hae-Jin Sung She received B.S. and M.S. degrees in Electrical Engineering from Changwon National University in 2012 and 2014, respectively. Her research interests are wind power system, superconducting generator. 


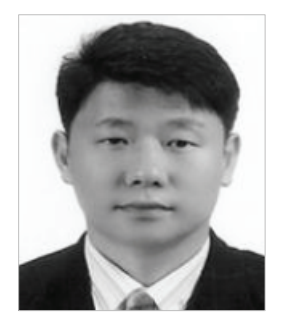

Minwon Park He received B.S degree in Electrical Engineering from Changwon National University in 1997 and his M.S. and Ph.D. degrees in Electrical Engineering from Osaka University in 2000 and 2002, respectively. His research interests are the development of the simulation model of power conversion equipment and renewable energy sources using EMTP type Simulators.

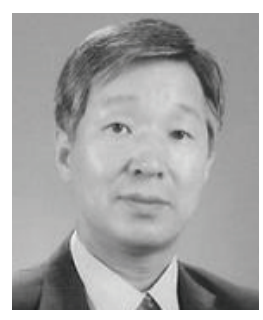

In-Keun Yu He received B.S degree in Electrical Engineering from Dongguk University in 1981 and his M.S. and Ph.D. degrees in Electrical Engineering from Hanyang University in 1983 and 1986, respectively. His research interests are electric energy storage and control systems, PSCAD/EMTDC and RTDS simulation studies, and renewable energy sources. 